\title{
Sonic Boom Carpet Computation as a Basis for Supersonic Flight Routing
}

\author{
Bernd Liebhardt ${ }^{\mathrm{a}}$, Klaus Lütjens ${ }^{\mathrm{b}}$ \\ German Aerospace Center (DLR), Hamburg, Germany \\ Majed Swaid ${ }^{\mathrm{c}}$ \\ Hamburg Technical University (TUHH), Germany \\ Matthes Müller ${ }^{\mathrm{d}}$ \\ Stuttgart University, Germany \\ Maik Ladewich $^{\mathrm{e}}$ \\ Hamburg University of Applied Sciences, Germany
}

\begin{abstract}
We lay out a methodology for optimizing supersonic flight paths by calculating sonic boom carpets of supersonic flight trajectories in specific atmospheric conditions, supposing that sonic booms must not make landfall. The process starts with route drafting, followed by iterative mission simulation, boom carpet computation, and flight path adaptation.
\end{abstract}

\section{Introduction}

$\mathrm{T}$ HE sonic boom caused by airplanes in supersonic flight is a phenomenon that has been known for a long time. NASA has started researching the sonic boom more than sixty years ago [1], yielding a vast amount of knowledge, data, theories, and methodologies that have constantly been disseminated to the scientific community, inducing even more insight in return.

The reason for needing to understand the sonic boom in the first place is that its sound causes startling and disturbance to people and animals on the ground even when the airplane passes by in high altitudes. An airplane travelling at supersonic speed transfers large amounts of energy to the surrounding air in the form of shockwaves. Those can travel dozens of miles and can be perceived as a distinctly sharp and cracking double bang. Consequently, civil supersonic flight over land was prohibited almost everywhere worldwide in the early 1970s. The Anglo-French supersonic airliner Concorde, introduced at that exact time and most possibly the cause for the new regulations, was confined to overwater routes, which crippled its already limited market potential and rendered its development program a commercial failure despite an eventual service life of 27 years. The competing Tupolev Tu-144 only completed some dozens of revenue flights and was removed from service not long after introduction. There was no other large-scale civil supersonic aircraft development program ever since.

For overcoming the sonic boom challenge and for implementing civil supersonics at long last, two distinct approaches can be followed:

Over the decades, NASA in particular was leading the development of methodologies for shaping airframes so that shockwaves are perceived as less disturbing when reaching the ground. The goal is to transform the sharp signature of pressure change, the so-called $\mathrm{N}$-wave, into a more benign form with slower pressure rise. This research has recently led to the QueSST flight test program that is aimed at demonstrating the validity of said "low-boom" technologies with the help of a dedicated X-plane [2]. However, imagining the general public being "boomed" legally and regularly by "the jet set" leaves room for doubt whether society will accept any change of rules at all, no matter the technological success and the eventual boom characteristic. In sum, this approach combines high market potential with high technological and regulatory risk.

${ }^{a}$ Dr.-Ing.; Research assoc.; DLR Air Transportation Syst., Blohmstr. 20, D-21079 Hamburg; Non-AIAA Member.

${ }^{\mathrm{b}}$ Head of department; DLR Air Transportation Systems, Blohmstrasse 20, D-21079 Hamburg; Non-AIAA Member.

${ }^{c}$ Research associate; Inst. of Air Transportation Systems, Blohmstr. 20, D-21079 Hamburg; Non-AIAA Member.

${ }^{\mathrm{d}}$ Undergraduate student; D-Stuttgart; Non-AIAA Member.

${ }^{\mathrm{e}}$ Graduate student; D-Hamburg; Non-AIAA Member.

American Institute of Aeronautics and Astronautics 
The second approach is that supersonic airplanes limit their speed over land, as it was done for Concorde. Flights are rerouted to seas and oceans where acceleration to supersonic cruise speeds happens, and time savings can be realized in spite of longer distances. This entails a much smaller market potential because the need for slow overland portions on many city pairs undermines the sense and purpose of high-speed flight. Nonetheless, this approach's upside is that no regulatory change is needed. Also, there are numerous destinations where supersonic flight routing can be done with only small detours, particularly in the North Atlantic and in Southeast Asia [3]. Additionally, overland flight could potentially happen at speeds up to about Mach 1.2 that prevent the sonic boom from reaching the ground, retaining some of the speed advantage $[4,5]^{\mathrm{f}}$. There might even be a substantial market for small supersonic airplanes with conventional "high-boom" design [6-8]. Taken all together, this approach implies a combination of lower technological and regulatory risk with a more limited market.

In this work, our research on the second approach is continued. A methodology is described for designing rulecompliant supersonic overwater flight paths ${ }^{\mathrm{g}}$ by taking sonic boom carpets into account.

\section{Theory and Modeling of Sonic Boom Propagation}

The moment an aircraft surpasses Mach 1, it starts producing shockwaves that move away from the aircraft at the speed of sound. Those pressure disturbances travel perpendicularly to the Mach cone, the latter constituting the shock front ${ }^{\mathrm{h}}$. On the way down, the shockwaves are gradually bent upward due to rising air temperatures (see Figure 1). Hence, they reach the ground only inside a "sonic boom carpet" of certain width below the flight path.

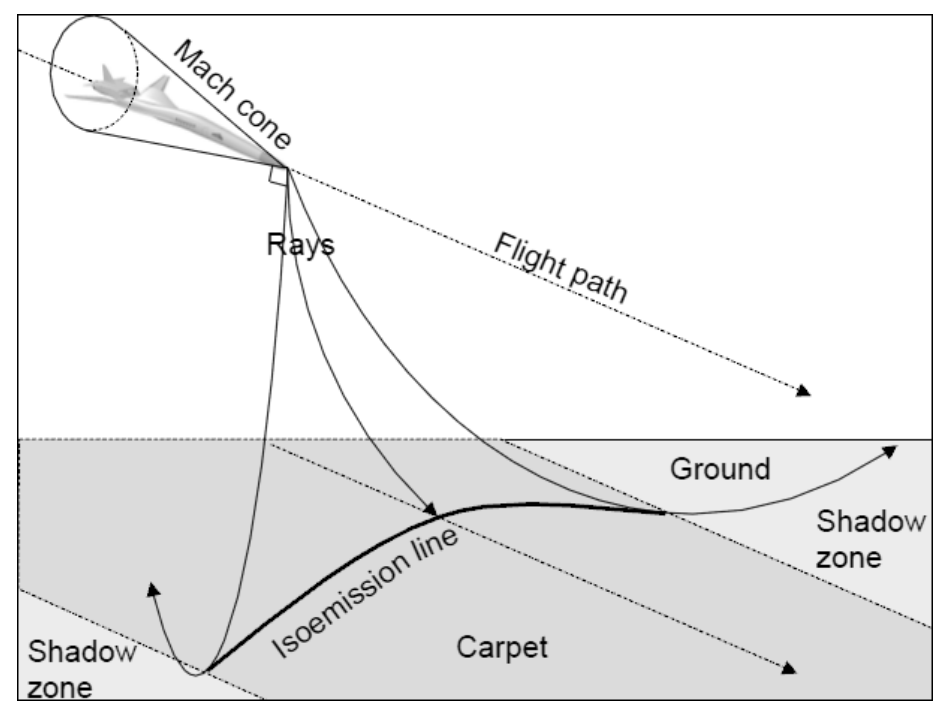

Figure 1. Sonic boom rays and carpet (modified from [9]).

This physical phenomenon of sound-bending is known to be governed by Snell's law which describes the relationship between the angles of incidence and refraction of light rays - or here, sonic "rays" - passing from one medium to another. In this case, the media are atmospheric layers with different temperatures and consequently, different speeds of sound. Snell's law for a shock wave ray in a moving atmosphere can be written as

$$
\frac{c_{1}}{\cos \theta_{1}}+u_{1}=\frac{c_{2}}{\cos \theta_{2}}+u_{2}
$$

where $c_{i}$ are the speeds of sound, $\theta_{i}$ are the sonic rays' angles relative to the horizontal plane, and $u_{i}$ are the horizontal wind speeds in the respective atmospheric layers.

${ }^{\mathrm{f}}$ In the U.S.A., civil supersonic flight is prohibited by Federal Aviation Regulation (FAR) 91.817. In many other regions, the sonic boom is not allowed to reach the ground, which in turn enables slightly supersonic Mach numbers. ${ }^{\mathrm{g}}$ In this paper, the expressions „flight path" and „flight route“ are used synonymously.

${ }^{\mathrm{h}}$ For the sake of simplicity, and as the result appears to be equivalent for the issue at hand, the aircraft can be imagined to produce only one main shock wave and to have only one frontal Mach cone. 

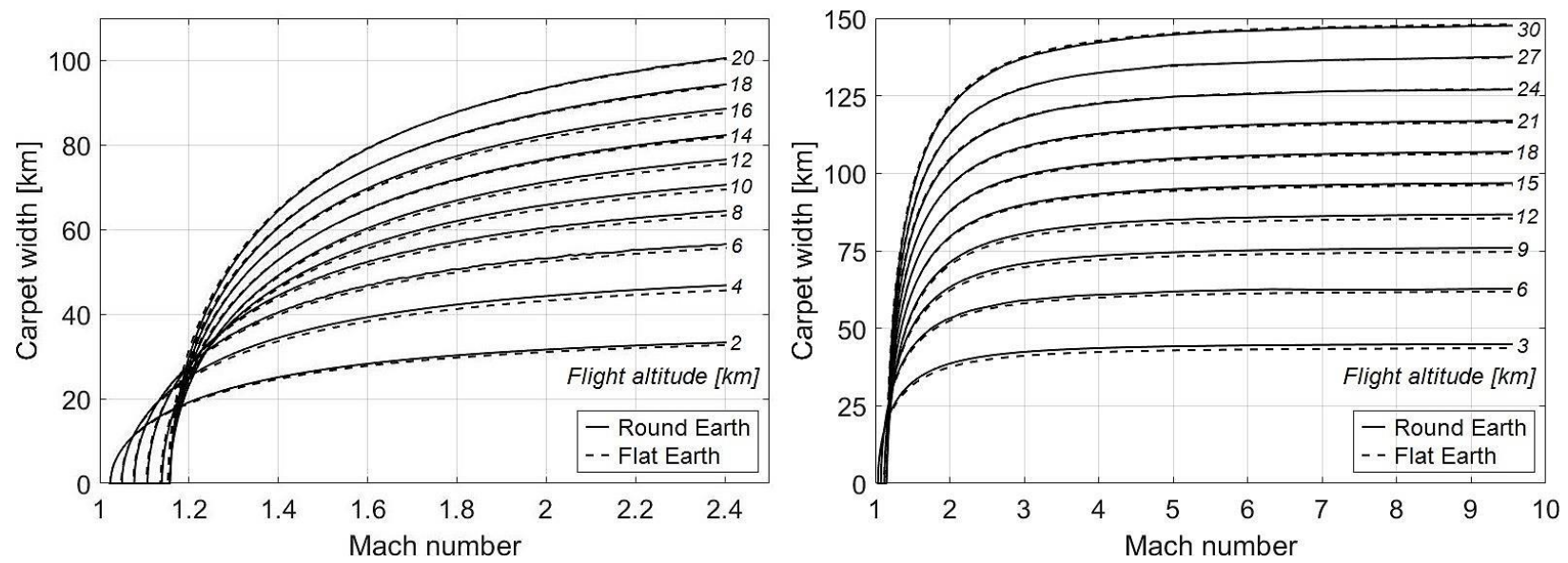

Figure 2. Theoretical carpet width over Mach number w.r.t. altitude, level flight, both for flat and round Earth, in International Standard Atmosphere. Left: Mach 1-2.5. Right: Mach 1-10.

Sonic boom propagation can be modeled by the well-established geometrical acoustics method of (sonic) ray tracing. The shock wave being emitted in all directions from the airplane's position, the path of one point on the wave front sent into a certain direction is followed over time, with the path always perpendicular to the wave front by definition. A comprehensive set of basic equations that govern sonic boom ray tracing is given by Onyeonwu [10], the main inputs being position, Mach number, wind vector, temperature, and emission angle.

Plotkin, Page, and Haering laid down a ray tracing methodology applicable to an ellipsoidal Earth [11] that builds on Schulten's equations for sound propagation in a Cartesian coordinate system [12] and Sofair's method for converting Cartesian to Geodetic coordinates and vice versa $[13,14]$.

The width of the sonic boom carpet primarily scales with Mach number and flight altitude (see Figure 2). Considering Concorde's Mach 2 speed and its 18 kilometers end-of-cruise altitude, the carpet width theoretically amounts to about 88 kilometers (47.5 nautical miles) in a standard atmosphere. In reality, shockwaves are carried by winds that can significantly shift the carpet's position and strongly increase its width on the downwind side [15]. This fact underlines the necessity to consider real atmospheres, including winds and temperature gradients, for boom carpet simulations.

\section{Procedure of Sonic Boom Carpet Computation}

The core of the presented methodology consists of a proprietary computer code that traces sonic ray paths over a spherical Earth in arbitrary atmospheres. Being similar in function to NASA's well-established ray tracing code embedded in PCBoom [16], it stops short of computing boom signatures and loudnesses, since our objective is for the (primary ${ }^{j}$ ) sonic boom not to make landfall and not to be heard at all. The algorithm's function was verified against PCBoom, where the respective solutions of test cases were found to match closely. There are several other sonic boom ray tracing codes run by either public research institutions or industry [17], but to date and to the best of our knowledge, only PCBoom and our code take account of the Earth's curvature. Rallabhandi notes that "primary boom carpets generally are not impacted by ellipsoid effects" [16]. However, we encountered ray runaways in our previous flat-earth implementation that grew worse with smaller, i.e. more accurate, step size. That is why we decided to adopt a curved earth, which eventually turned out successful at eliminating said runaways.

For determining the extent of the sonic boom carpet, sonic rays are emitted downward from the aircraft's position in varying initial angles and traced on their way through the atmosphere. Rays are relinquished as soon as they regain altitude. The carpet edges are constituted by the points of impingement of the two marginal rays that just make it to the ground on the starboard and port sides, respectively (cf. Figures 1 and 3).

This procedure is repeated for an adequate number of positions on a supersonic flight trajectory. Finally, the encountered points of impingement are connected to depict the full sonic boom carpet.

\footnotetext{
${ }^{i}$ The World Geodetic System of 1984 reference ellipsoid (WGS 84) is used as the Earth's shape.

${ }^{\mathrm{j}}$ For the time being, we chose to ignore secondary booms (either by ground or over-the-top deflection) because their loudness is probably below any of the thresholds that are discussed for overland supersonic flight.
} 

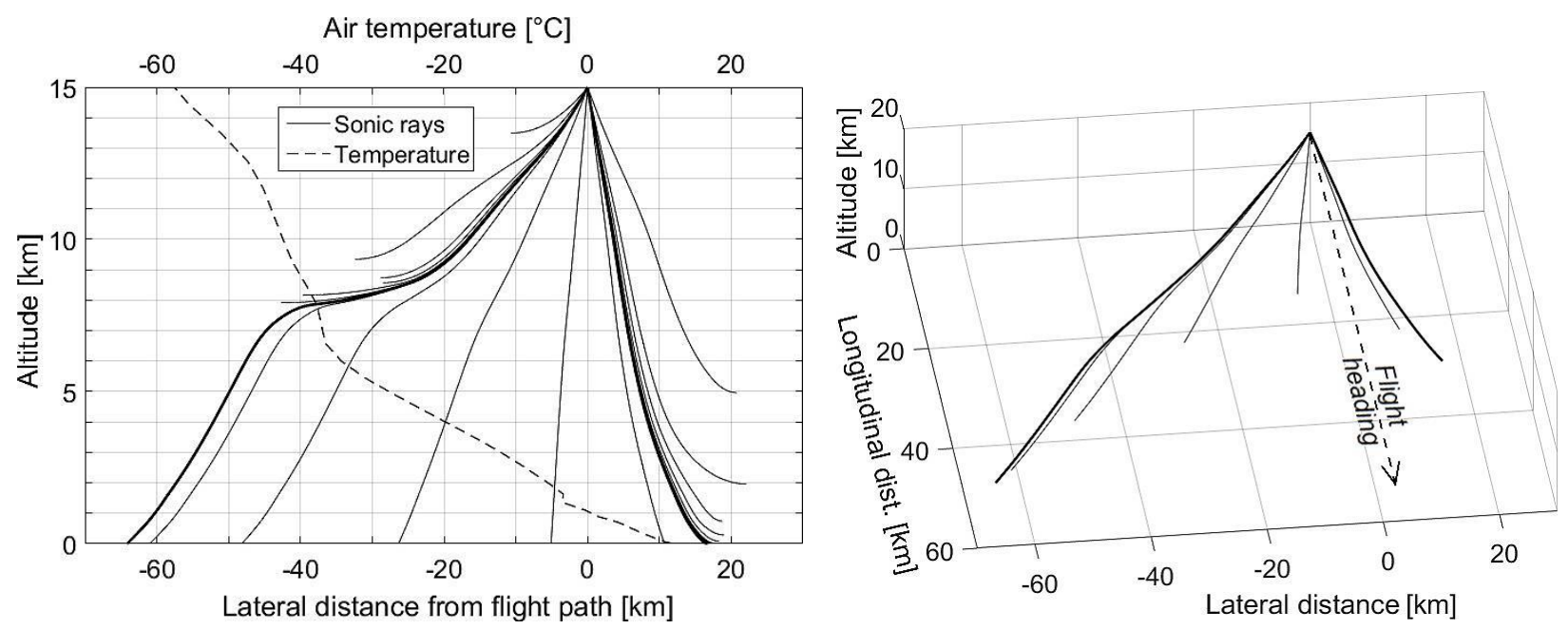

Figure 3. Example of sonic ray tracing in a certain atmosphere for determining boom carpet width. Left: Frontal view; marginal rays as bold lines. Right: 3-D view (ground-reaching rays only).

NB: strong crosswinds, ray curvature depending on temperature gradients.

The atmospheres used for the present study originate from the European Centre for Medium-Range Weather Forecasts (ECMWF) and apply to one specific point in time (e.g., 6:00 hours on January 1,2015). They contain air pressure, density, temperature, and horizontal as well as vertical winds. The data were extracted for the whole globe in resolutions of $0.75^{\circ}$ in longitude, $0.75^{\circ}$ in latitude, and 60 position-specific altitudes from ground level up to about 60 kilometers with downward-increasing resolution. They are available for at least eight times of day over the course of several years.

\section{Process of Flight Route Design and Optimization}

In a former work, we detailed a design chain for supersonic overwater flight paths that considered sonic boom carpets only by supposing one allegedly sufficient distance to shores [3]. This shortcoming is amended in the work at hand by extending the design chain with sonic boom carpet computations.

Below, the new process is laid out that is aimed at optimizing a flight route, i.e. minimizing flight time by minimizing detours and maximizing the overwater flight portions concurrently, for a given point in time (also see Figure 4).

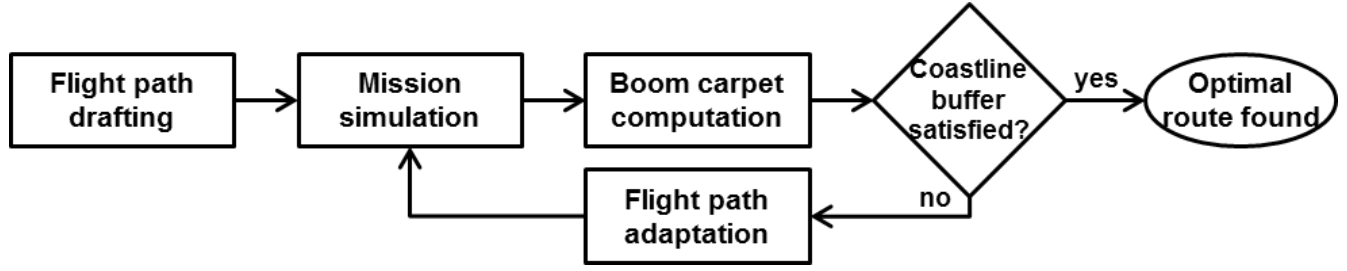

Figure 4. Route optimization chain.

\section{A. Flight path drafting.}

A flight path is drafted on the Google Earth platform ${ }^{\mathrm{k}}$ for a given city pair. The following parameters are taken into account:

- The aircraft's subsonic and supersonic ranges to determine whether a non-stop mission can be flown or a technical stop must be performed at an adequate airport.

- The aircraft's cruise speed to find a compromise between a high overwater percentage and a low detour percentage, respectively, of the total distance, with the goal of minimizing flight time.

\footnotetext{
${ }^{\mathrm{k}}$ Available at www.google.com/earth.
} 
- The aircraft's cruise speed and an adequate maximum load factor for passenger comfort (e.g., 1.2) to predefine minimum turn radii ${ }^{1}$.

- The habitation status of islands, assuming that uninhabited and barren islands can be disregarded.

- A preliminary distance to shores.

Figure 5 shows an accordingly designed flight route between London and Jeddah. A code of the subsonic/ supersonic distance segmentation is added to the route description in Google Earth.

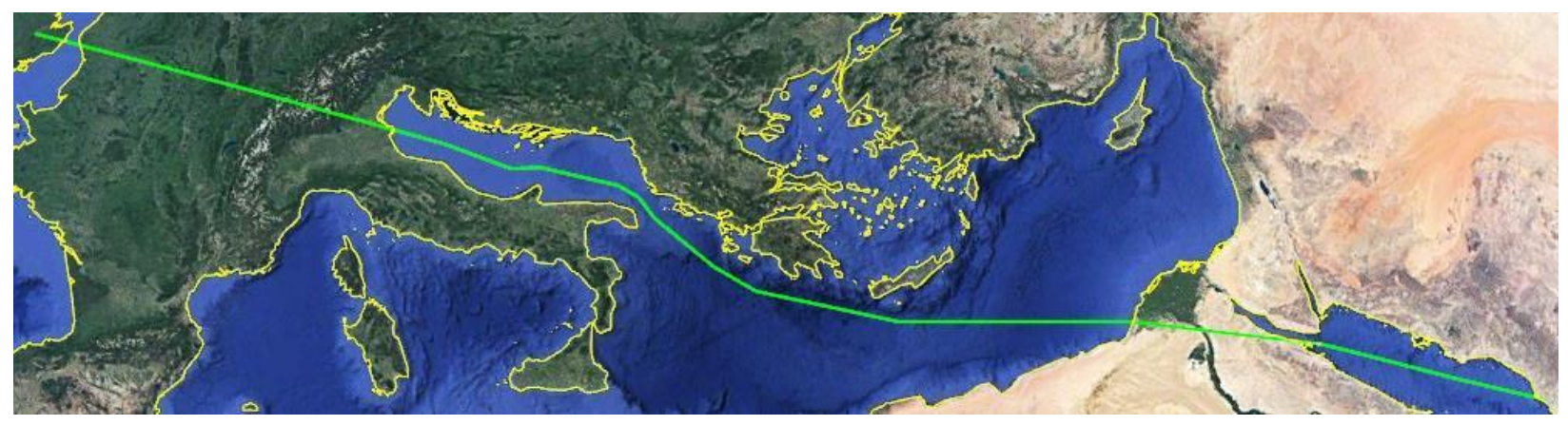

Figure 5. Drafted London-Jeddah flight route [Google Earth].

\section{B. Mission simulation.}

A mission simulation is run on a proprietary algorithm to determine the flight trajectory. It uses the following parameters:

- The flight route imported from Google Earth.

- Aircraft performance specifications (masses, aerodynamic polars, engine maps, segment speeds, ...).

- The airports' elevations.

- Spatially discretized atmospheric data.

Taking a certain Mach 1.6 civil supersonic aircraft design as a basis, the calculated altitudes and Mach numbers, respectively, over the flight distance on the drafted London-Jeddah flight route are shown in Figure 6. Overwater segments are flown at supersonic cruise speed with a climbing cruise, starting above all regular subsonic traffic which tops out at $51.000 \mathrm{ft}$. In contrast, overland segments maintain flight levels with intermittent step climbs.

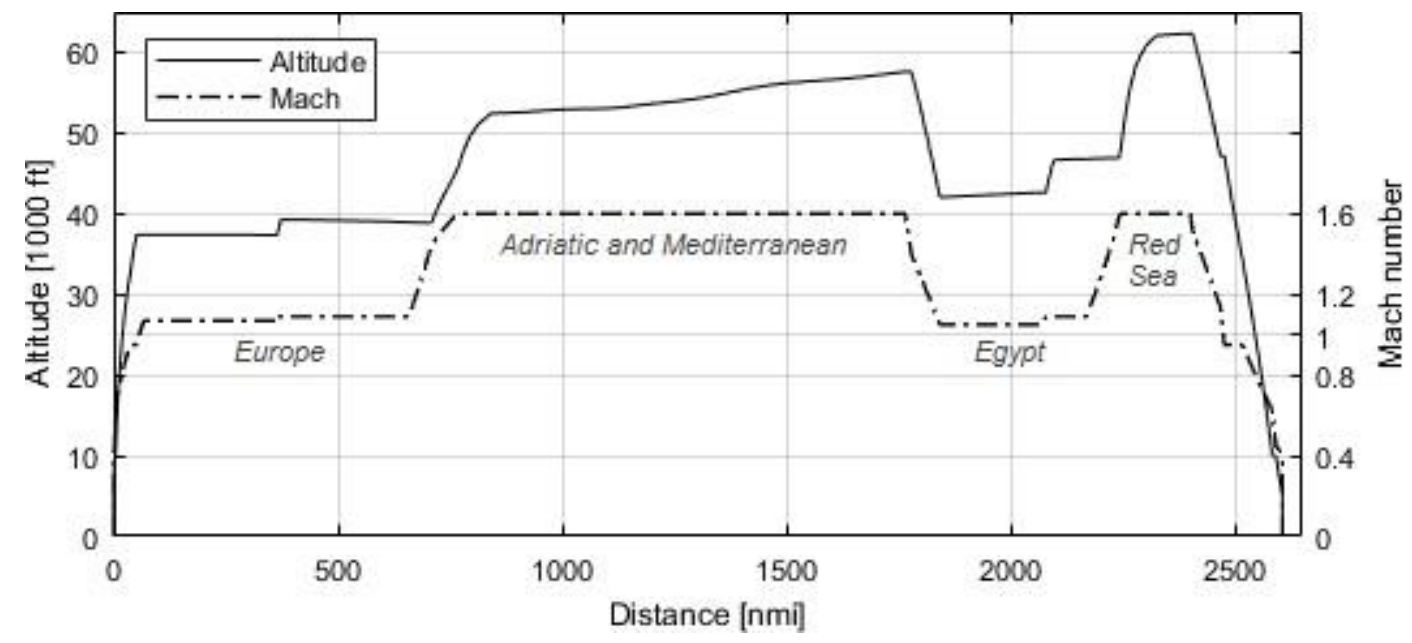

Figure 6. Vertical trajectory and Mach numbers on initial London-Jeddah route. Atmosphere of January 1, 2015, 6:00 hours UTC (2015-01-01-06)

\footnotetext{
${ }^{1}$ For instance, a cruise Mach number of 1.6 (ca. $472 \mathrm{~m} / \mathrm{s}$ or 917 knots in the tropopause) and a maximum load factor of 1.2 results in a minimum turn radius of ca. 34.4 kilometers (18.6 nautical miles).
} 
Further, the speed restriction of Mach cutoff flight is employed [4]: Using ray tracing, a cruise Mach number is determined that prevents sonic booms from penetrating a certain "cutoff altitude", e.g. $10.000 \mathrm{ft}$. This enables slightly supersonic speeds that are subject to the atmospheric temperature difference between flight altitude and cutoff altitude. Coincidentally, a significant reduction of fuel efficiency ensues due to flying in the highest-drag transonic region. As an alternative, subsonic flight is possible for regions that prohibit supersonic flight entirely.

\section{Boom carpet computation.}

Sonic ray tracing is performed for the whole calculated flight trajectory using the same atmosphere as for mission performance simulation. The resulting sonic boom carpets are put out in Google Earth format, see Figure 7. In this case, it can be observed that the carpet infringes numerous coast lines. Also, supersonic accelerations and decelerations apparently happen too late in the mission.

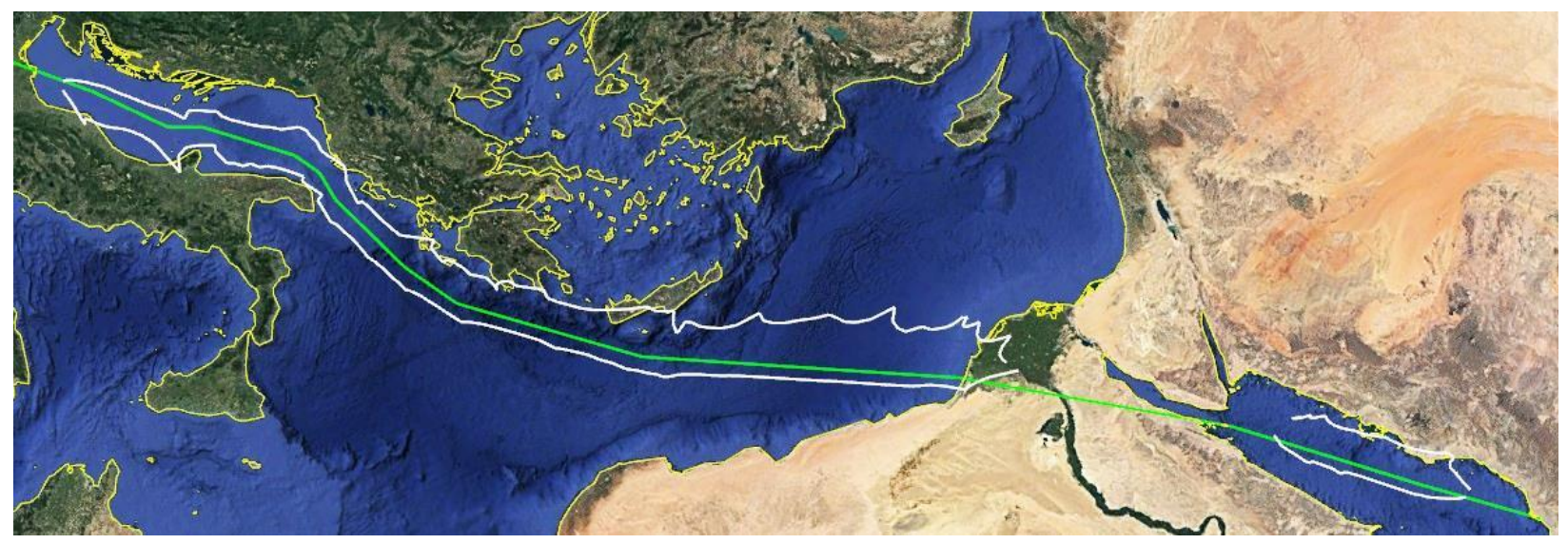

Figure 7. Sonic boom carpet of initial London-Jeddah trajectory, 2015-01-01-06 atmosphere [Google Earth].

\section{Flight path adaptation.}

The original flight path is adapted manually according to the encountered boom carpet infringements. In the case at hand, the path is moved laterally at several locations, and a lower-speed segment is introduced at the Strait of Otranto (the Adriatic exit) because the carpet exceeds the strait's minimum width of 73 kilometers (39.4 nmi).

\section{E. Iteration.}

Subsequently, steps B to D are repeated iteratively until the calculated sonic boom carpet of step C exhibits no more coastline violations. Figure 9 shows the resulting route and boom carpet, and Figure 9 shows the final trajectory. Minimum flight time is achieved by minimizing detours and maximizing overwater portions.

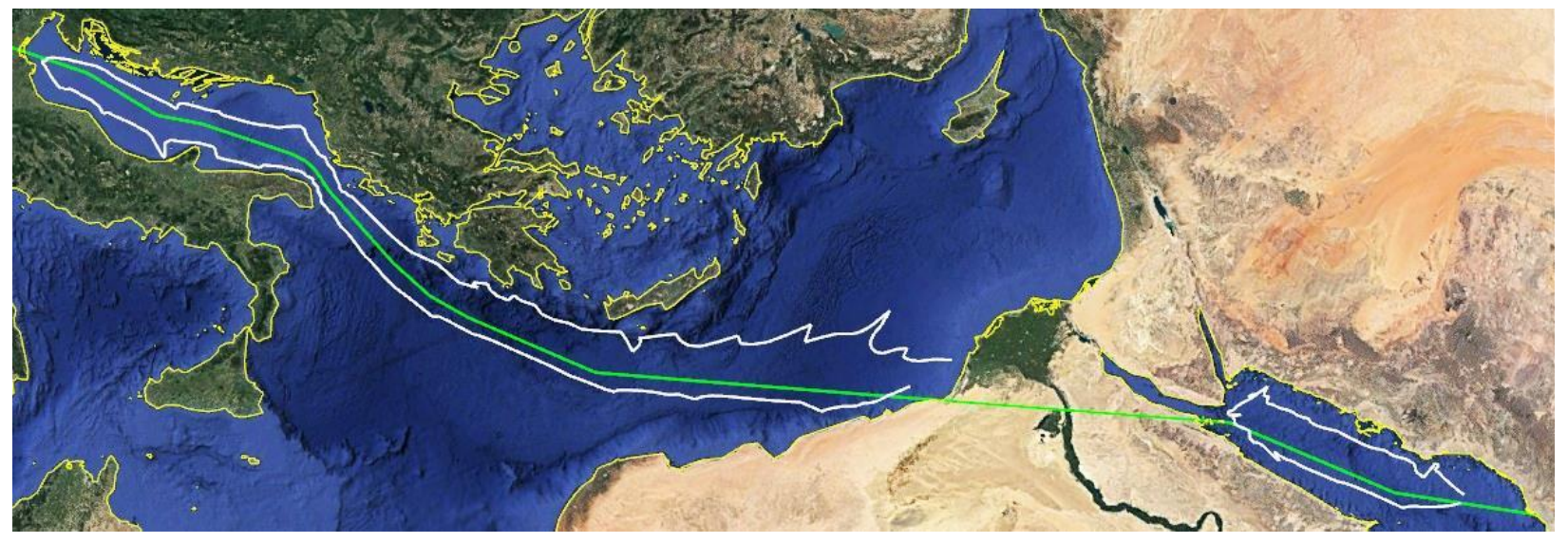

Figure 8. Final London-Jeddah route and sonic boom carpet, 2015-01-01-06 atmosphere [Google Earth]. 


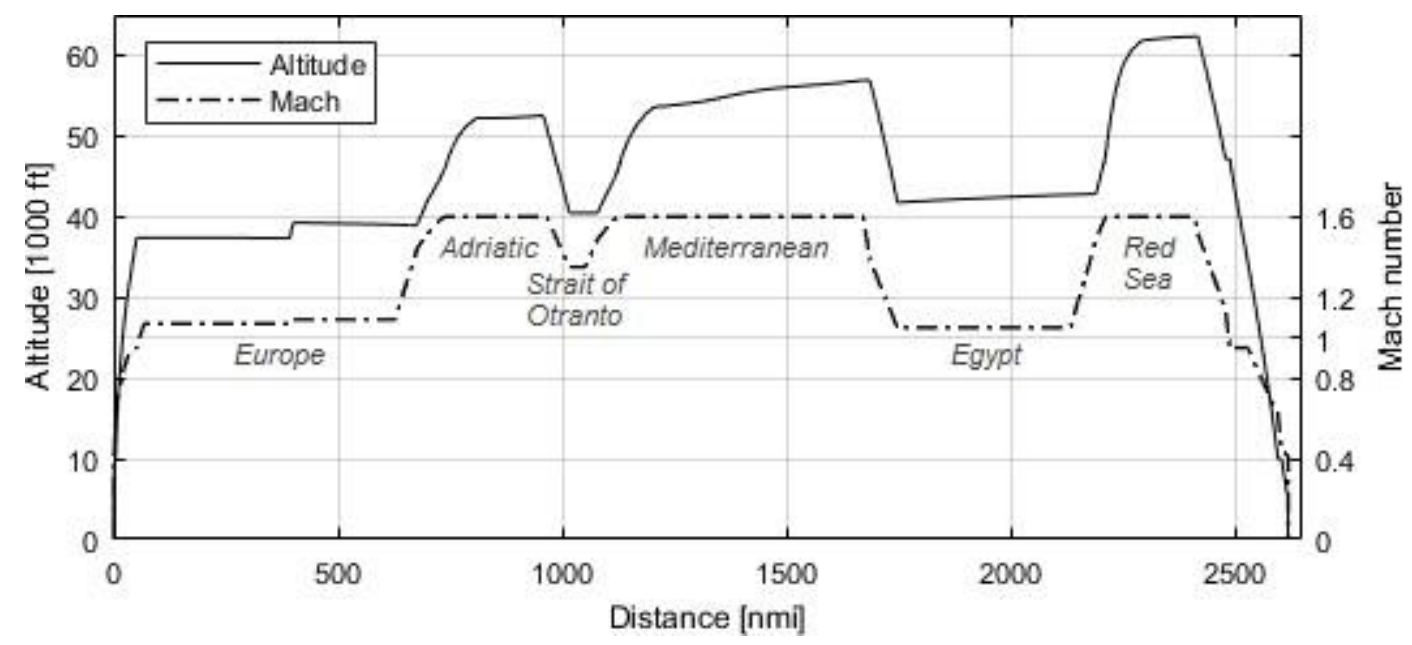

Figure 9. Vertical trajectory and Mach numbers on final London-Jeddah route, 2015-01-01-06 atmosphere.

\section{Miscellaneous Discussion}

\section{A. Fully automatizing the supersonic flight route optimization chain.}

The mission simulation and sonic boom carpet computation parts of the optimization chain are already automatized. Automatic flight path generation has been tried by us and by others, but was found extremely difficult due to the need to take various complicating parameters into account, e.g. aircraft flight performance, specific overflight regulations, and earth surface discretization. So for now, we will adhere to drafting flight paths manually and to draw on our comprehensive flight path database (also cf. [3]).

Flight path adaptation, however, can probably be automatized with some effort, which we might attempt in the future. If successful, the whole route optimization process would only require a drafted flight path as an input.

\section{B. Lateral cutoff.}

In real flight experiments producing actual sonic booms and measuring their strength and extent on the ground (the FaINT project [18]), Cliatt, Haering, Arnac, and Hill dealt with the problem of defining the exact boundary ("lateral cutoff") of sonic boom carpets. They found that evanescent waves right beyond that cutoff position, being perceived as a rumble and decaying exponentially in their course, can still be well discerned from ambient noise within a few miles' distance and can reach considerable loudness. Eventually, they postulate $65 \mathrm{~dB}^{\mathrm{PL}} \mathrm{SEL}_{\mathrm{S}}$ as a threshold for the definition of the acoustic lateral cutoff.

Further, traditional ray tracing was found insufficient for positioning the acoustic lateral cutoff because it does not accurately model the transition region and because it neglects evanescent waves. As a relief, an acoustic model such as the one theorized by Coulouvrat could be implemented [19]. However, notable noise was only recorded 1-2 nautical miles beyond the predicted cutoff, which in turn would render distance buffers a simple solution.

\section{Altitude cutoff.}

During the above-mentioned FaINT project, a second flight campaign was conducted to measure the loudness of evanescent waves below the cutoff altitude [20]. Using the results, an empirical equation was developed that describes the relationship between on-ground loudness, cutoff altitude, threshold Mach number, and flight Mach number. This equation could be used to choose the right cutoff altitudes and flight Mach numbers, respectively, in order to comply with an arbitrary loudness threshold on the ground.

Coincidentally, it was cautioned that the desired loudness could easily and widely be exceeded due to even small atmospheric variations. If confirmed, this finding would put a strain on the whole concept of overland Mach cutoff flight, and it might even impact low-boom high-speed supersonic overland flight.

In any case, topographic data have to be implemented for realistic overland simulations and real-world applications. This capability will feature in a later version of our simulating environment. For this paper's simulations, a general cutoff altitude of 10,000 feet was used, which seemed sufficient for most regions. However, Mach cutoff flights produce coalescing shock waves (a so-called caustic) exactly at cutoff altitude, resulting in a powerful "super-boom" [4]. In our fictive use-case above, overflying the Alps that reach above 10,000 feet could theoretically cause disaster by triggering snow avalanches. 


\section{Validation of simulated boom carpets.}

The presented methodologies have to be validated with the help of actual flight tests. Looking back at NASA's FaINT project $[18,20]$, this seems to be a challenging task. Atmospheric conditions have to be predicted as accurately as possible, considering the actual duration of the flight, and the effect of unpredictable turbulence has to be quantified statistically. All this probably requires extensive flight campaigns, which could hypothetically be included in the certification flight tests.

Moreover, we found computed boom carpet widths to be extremely sensitive to both the chosen step size of ray propagation and the minimum variation of emission angle. To tackle this factor of insecurity, we opted for very accurate modeling, inferring high computational effort, and for adaptive step sizes.

\section{E. Robust flight routing.}

In contrast to optimizing flight routes for single flights and their respective unique atmospheric condition, flight paths can be developed that are viable always or most of the time. This is done by taking into account a large number of discrete atmospheres and placing the route thus that sonic booms would never, or just in extreme cases, make landfall. This approach would infer a penalty compared to the actual optimum route, both regarding flight time and fuel consumption, whereas it would ease the need for recurring flight route adaptations.

For the acquainted London-Jeddah route and its optimized flight path from above, sonic boom carpet computations were performed for 365 atmospheres of the year 2015, using differing times of day. In Figure 10, countless coastal infringements can be seen, whereas carpet half-widths much above 100 kilometers, or 50 nautical miles, were all but seldom. This illustrates the tremendous effect of atmospheric variability on sonic boom carpets.

Also, it appears that for this route which is particularly challenging due to its narrow passages, robust flight routing probably makes less sense than for others. On the utterly important London - New York city pair, for instance, the flight path simply needs to be moved farther offshore to make it more robust (which, coincidentally, applies to most supersonic flight routes). Anglo-French Concorde was operated on pre-defined flight paths that could place the aircraft more than 150 nautical miles away from Newfoundland, Nova Scotia and Nantucket Island in cases of unfavorable winds.

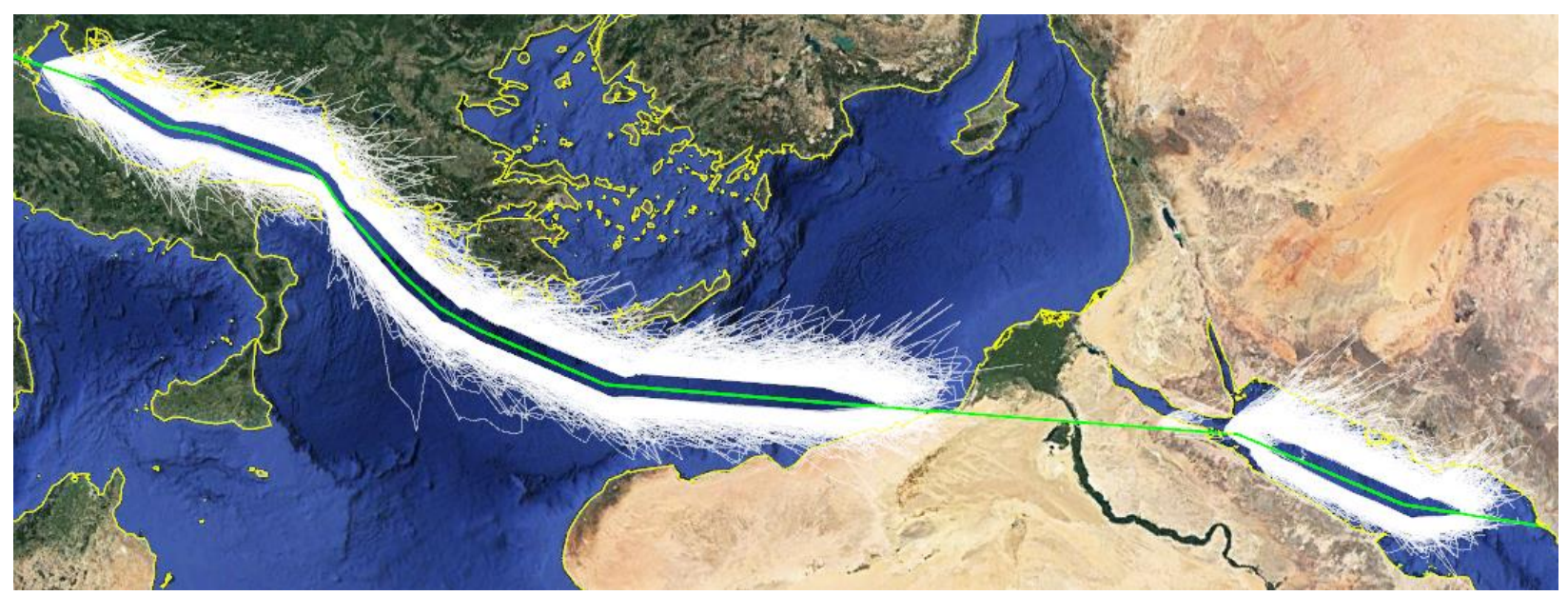

Figure 10. All-year boom carpets on the London-Jeddah route optimized for 2015-01-01-06 [Google Earth].

\section{F. Downstream applications of viable flight routes.}

The mediate goal of our route optimization work is to provide substantiated data for operational planning, particularly flight time and fuel consumption. Together with other data and methods that we have established, it enables comparing subsonic to supersonic flights, drafting possible supersonic airline networks, and assessing supersonic business plans.

Further, in the probable case that sonic boom carpet simulations prove valid and useful, they will be sought after in future supersonic operations. This would make the discussed tool chain a possible basis for commercial products.

Finally, the ability to accurately predict sonic boom carpets, plan flight routes accordingly, and avoid sonic booms on land could support public acceptance of supersonic flight. 


\section{Conclusion}

A methodology was presented for designing supersonic flight routes by taking into account sonic boom carpets. As sonic booms are not allowed to touch land, flight paths are placed over water and rerouted so that the underlying boom carpet does not infringe coastlines. Real discretized atmospheres including temperatures and winds are used for considering the significant influence of atmospheric variability on the extent and position of sonic boom carpets. The design process consists of (manual) flight path drafting, followed by an iteration of (automatic) mission simulation, (automatic) boom carpet computation, and (manual) flight path adaptation. Flight path adaptation is planned to be automatized in the future. Further, topography shall be implemented for adapting the sonic boom cutoff altitude in order to keep the sonic boom from touching the ground on just-about-supersonic overland flights.

\section{References}

[1] Maglieri, D. J., Sonic boom. Six decades of research, Langley Research Center, Hampton, Va., 2014.

[2] Coen, P., and Richwine, D., "Status and plans for NASA's Quiet SuperSonic Technology (QueSST) aircraft design," The Journal of the Acoustical Society of America; Vol. 141, No. 5, 2017, p. 3461. doi: 10.1121/1.4987181.

[3] Liebhardt, B., Linke, F., and Dahlmann, K., "Supersonic Deviations: Assessment of Sonic-Boom-Restricted Flight Routing," Journal of Aircraft; Vol. 51, No. 6, 2014, pp. 1987-1996. doi: 10.2514/1.C032591.

[4] Plotking, K. J., Matisheck, J. R., and Tracy, R. R., "Sonic Boom Cutoff Across the United States," 2008, AIAA 2008-3033, https://arc.aiaa.org/doi/10.2514/6.2008-3033, [retrieved 14 March 2019].

[5] Kästner, M., and Heimann, D., "Sound propagation of sonic booms through real atmospheres emitted from a new supersonic business aircraft," 2007 Meteo France; Vol. 2, pp. 781-784.

[6] Liebhardt, B., and Lütjens, K., "An Analysis of the Market Environment for Supersonic Business Jets," Deutscher Luft-und-Raumfahrt-Kongress, 2011, http://elib.dlr.de/75275/.

[7] Liebhardt, B., Lütjens, K., and Gollnick, V., "Estimation of the Market Potential for Supersonic Airliners via Analysis of the Global Premium Ticket Market," 11th AIAA Aviation Technology, Integration, and Operations (ATIO) Conference, 2011; AIAA 2011-6806, http://elib.dlr.de/75274/.

[8] Liebhardt, B., Lütjens, K., Tracy, R. R., and Haas, A. O., "Exploring the Prospect of Small Supersonic Airliners - A Business Case Study Based on the Aerion AS2 Jet," AIAA Aviation Conference, Denver, CO, 2017; AIAA 2017-3588, http://elib.dlr.de/111925/.

[9] Coulouvrat, F., "The Challenges of Defining an Acceptable Sonic Boom Overland," 2009; AIAA 2009-3384.

[10] Onyeonwu, R. O., The effects of wind and temperature gradients on sonic boom corridors, Univ. Inst. for Aerospace Studies, Toronto, Ont., 1971.

[11] Plotkin, K. J., Page, J. A., and Haering, E. A., "Extension of PCBoom to Over-The-Top Booms, Ellipsoidal Earth, and Full 3-D Ray Tracing," 2007, AIAA 2007-3677.

[12] Schulten, Johan B. H. M., Computation of aircraft noise propagation through the atmospheric boundary layer, Nationaal Lucht- en Ruimtevaartlaboratorium (NLR), Amsterdam, 1997.

[13] Sofair, I., Improved Method for Calculating Exact Geodetic Latitude and Altitude, Defense Technical Information Center, Ft. Belvoir, 1995.

[14] Sofair, I., "Improved Method for Calculating Exact Geodetic Latitude and Altitude Revisited," Journal of Guidance, Control, and Dynamics; Vol. 23, No. 2, 2000, p. 369. doi: 10.2514/2.4534.

[15] Blumrich, R., Coulouvrat, F., and Heimann, D., "Meteorologically induced variability of sonic-boom characteristics of supersonic aircraft in cruising flight," The Journal of the Acoustical Society of America; Vol. 118, No. 2, 2005, pp. 707-722.

[16] Rallabhandi, S. K., "Sonic Boom Prediction and Mitigation using Three-Dimensional Earth Effects," 2018, AIAA 2018-2848, https://arc.aiaa.org/doi/abs/10.2514/6.2018-2848, [retrieved 14 March 2019].

[17] Rallabhandi, S. K., and Loubeau, A., "Summary of Propagation Cases of the Second AIAA Sonic Boom Prediction Workshop," Journal of Aircraft, 2018, pp. 1-20. doi: 10.2514/1.C034805.

[18] Cliatt, L. J., II, Haering, E. A., JR., Arnac, S. R., and Hill, M. A., "Lateral Cutoff Analysis and Results from NASA's Farfield Investigation of No-Boom Thresholds," 2016, TM-2016-218850, https://ntrs.nasa.gov/search.jsp?R=20160003115, [retrieved 14 March 2019].

[19] Coulouvrat, F., "Sonic boom in the shadow zone: A geometrical theory of diffraction," The Journal of the Acoustical Society of America; Vol. 111, No. 1, 2002, pp. 499-508. doi: 10.1121/1.1371973.

[20] Cliatt, L. J., II, Hill, M. A., and Haering, E. A., JR., "Mach Cutoff Analysis and Results from NASA's Farfield Investigation of No-Boom Thresholds," 2016, DFRC-E-DAA-TN30184, https://ntrs.nasa.gov/search.jsp?R=20160007348, [retrieved 14 March 2019]. 